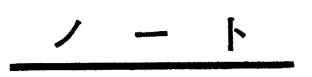

\title{
A Simple Method for Determination of Oil Content of Seed and Its Fatty Acid Composition by GLC Using Small Amount of Sample
}

\author{
Priya Ranjan KumaR* and Kenshiro Fujimoto \\ Faculty of Agriculture, Tohoku University \\ (1-1, Tsutsumidori-Amamiyacho, Sendai)
}

\begin{abstract}
A simple method for determination of oil content and fatty acid composition in small seed sample $(>2 \mathrm{mg})$ is presented using methyl heptadecanoate as internal standard. Using this method, the possibility of loss of oil is eliminated, and simultaneous extraction and methyl esterification of oil in a test tube can be efficiently carried out. A comparison of the present method with conventional one revealed a close agreement with regard to oil content and fatty acid composition of two major rapeseed crops, viz., Brassica napus and Brassica campestris.
\end{abstract}

In Cruciferous oilseeds, the long chain mono= ethenoid acids $\left(\mathrm{C}_{20: 1}, \mathrm{C}_{22: 1}\right)$ are major fatty acids. Studies carried out with experimental animals fed the diets containing rapeseed oil high in erucic acid showed immediate development of lipidosis ${ }^{1,2)}$ indicating thereby that the long chain erucic acid can not be metabolized effectively $^{3}$. Such results necessitated the breed $=$ ing for Cruciferous oilseed crops free from erucic acid so that it may command premium in food industry. In plant breeding studies where the hybridized seeds obtained are usually limited in quantity, it is necessary to have a method for precise determination of oil content and fatty acid composition. Downey and Craig ${ }^{4}$ used dibutyl sebacate as an internal standard for determination of oil content in rapeseed. Since this substance is a butyl ester, it was added at the last stage so as to avoid the transition to methyl ester. In the present study, instead of butyl sebacate, methyl heptadecanoate $\left(\mathrm{C}_{17: 0}\right)$ was used. This ester was considered fairly suitable as the internal standard since it contained less than $0.1 \%$ of the total fatty acids in Cruciferous oilseeds ${ }^{5}$. Further, as it is the

* Visiting scholar ; Permanent address : Department of Plant Breeding, Dry Farming Research Center, Haryana Agricultural University, Bawal-123501, India. methyl ester, it can be added in the beginning of the experiment which would eliminate the possibility of the error in oil content caused by the loss of oil during extraction and trans= methylation. Another advantageous feature of the present method is the simultaneous extraction and methylation of oil which makes this method more rapid. Apart from this, instead of air condenser as used by Downey and Craig ${ }^{4}$ for carrying out the reflux, a single screwed test tube is used for warming the solvent. This enables the simultaneous preparation of a large number of seed samples for gas-liquid chroma= tography.

\section{Experimentation}

Seed samples $(>2 \mathrm{mg})$ were dried in an electric oven at $100^{\circ} \mathrm{C}$ for one hour. Subsequently it was weighed and crushed in a test tube having a screw cap (in case of small sample) with a glass rod. Then the internal standard was added depending upon the sample size, for example, in $5 \mathrm{mg}$ seed sample, $1 \mathrm{ml}(0.03 \%)$ of the benzene solution of methyl ester of heptadecanoate, obtained from the Applied Science Co. Ltd., U.S.A. was added for estimating the oil content on gas-liquid chro= matography.

Thereafter, $2.5 \mathrm{ml}$ of the mixture of methanol, 
acetyl chloride and benzene (20:1:4) was added in a test tube for extraction and methyl= ation of oil. Test tube screwed properly was, then heated on a water-bath at $70^{\circ} \mathrm{C}$ for an hour. After cooling at room temperature, the contents were filtered into a separating funnel $(50 \mathrm{ml}) .5 \mathrm{ml}$ of petroleum ether was then added to the separating funnel and shook well to get the methyl ester of fatty acids dissolved. Saturated solution of $\mathrm{NaCl}$ was added 3 to 4 times and shook well till the emulsion layer disappeared. Then the methyl ester of fatty acids were transferred to a test tube and de= hydrated with small amount of anhydrous $\mathrm{Na}_{2}$ $\mathrm{SO}_{4}$. After an hour, the supernatant liquid was taken into a Kjeldahl-type flask, benzene and petroleum ether were evaporated under reduced pressure using a rotary evaporator. The methyl ester was then transferred into a small test tube and stored in a refrigerator $\left(-25^{\circ} \mathrm{C}\right)$ until the analysis was carried out.

Composition of fatty acid was determined by gas-liquid chromatography (Model JGC 20 $\mathrm{KR}$ ) using $1 \mathrm{~m} \times 3 \mathrm{~mm}$ glass column packed with

Table-1 Oil contents and fatty acid composition in Brassica campestris (variety-Torch) and Brassica napus (variety-Tower) fol= lowing the standard weighing and gasliquid chromatography methods.

\begin{tabular}{|c|c|c|c|c|}
\hline & \multicolumn{2}{|c|}{$\begin{array}{l}\text { Standard } \\
\text { weighing } \\
\text { method** }\end{array}$} & \multicolumn{2}{|c|}{ GLC method } \\
\hline & \multicolumn{4}{|c|}{ Varieties } \\
\hline & Torch & Tower & Torch & Tower \\
\hline Number of seeds & 47 & 28 & 13 & 8 \\
\hline Weight of seeds (mg) & 102.7 & 99.4 & 22.7 & 24.0 \\
\hline Oil content $(\%)$ & 38.3 & 39.1 & 39.1 & 41.3 \\
\hline \multicolumn{5}{|l|}{$\begin{array}{l}\text { Fatty acid } \\
\text { composition }(\%)\end{array}$} \\
\hline $16: 0$ & 3.9 & 4.0 & 4.1 & 4.0 \\
\hline $18: 0$ & 2.0 & 2.9 & 2.1 & 2.7 \\
\hline $18: 1$ & 61.6 & 59.5 & 61.1 & 59.4 \\
\hline $18: 2$ & 20.2 & 19.8 & 21.2 & 19.7 \\
\hline $18: 3$ & 9.7 & 12.1 & 9.1 & 12.1 \\
\hline $20: 1$ & 1.6 & 1.1 & 1.8 & 1.0 \\
\hline $22: 1$ & 0.7 & 0.6 & 0.6 & 0.5 \\
\hline Others & 0.3 & 0.0 & 0.0 & 0.6 \\
\hline
\end{tabular}

* Fatty acid composition was determined by GLC after estimating the oil content of seeds by weigh= ing the ether extract.
$10 \%$ LAC-2 R-446 on 80 100 mesh, acid washed Chromsorb W. A column temperature of $190^{\circ} \mathrm{C}$ was used with nitrogen as the carrier gas. De= tection was carried out by flame ionization. In quality breeding programmes, a large numder of seed samples often need to be analysed for fatty acid composition on gas-liquid chromato graphy. To facilitate the analysis of large num= ber of seed sample in a short period, 10\% LAC column was used instead of DEGS column. With this change, the period of separation of fatty acid was shortened from 50 to 15 minutes. The composition of fatty acid was estimated from the areas obtained by measuring the heights of peaks of curves and width of the half height. The oil content, on the other hand, was calcu= lated by the following formula :

Total area of fatty acids $\times$ Amount of $\mathrm{C}_{17: 0}(\mathrm{mg})$ Area of $\mathrm{C}_{17: 0} \times$ Amount of seeds $(\mathrm{mg})$

This gives precisely the amount of total methyl ester. Since the difference between the total methyl ester and triglyceride is very small, therefore, in place of total methyl ester, total oil can be reasonably used.

As is evident from Table-1, the analytical results on oil content in two major rapeseed crops, viz., Brassica campestris (variety-Torch) and Brassica napus (variety-Tower) using the present method are in close agreement with conventional weighing method.

Authors are grateful to Dr. S. Tsunoda, Pro= fessor of Plant Breeding for providing necessary facilities and encouragement. Grateful thanks are also due to Dr. T. Kaneda, Professor of Food Chemistry, Faculty of Agriculture, Tohoku Uuiversity, for critically going through the manuscript and valuable suggestions.

(Received Sept, 27, 1976)

\section{References}

1) J.L. Beare-Rogers, Proc. Intern. Conf. Rape= seed, Ste. Adele, Canada, 20-23 Sept. (1970), p. 450 .

2) J.L. Beare-Rogers, Lipids, 11, 287 (1976)

3) G. Röbbelen, Proc. 6 th Congr. Eucarpia, Cambrige, (1971) p. 207.

4) R.K. Downey, B.M. Craig, J. Am. Oil Chem. Soc., 41, 475 (1964)

5) P.R. Kumar, S. Tsunoda, Unpublished. 